\title{
Brazilian dentists' perception of dentin hypersensitivity management
}

Livia Fávaro ZEOLA ${ }^{(a)}$ (1)

Daniela Navarro Ribeiro TEIXEIRA(a)

Alexia da Mata GALVÃO(a)

Paola Gomes SOUZA ${ }^{(a)}$

Paulo Vinícius SOARES(a)

(a) Universidade Federal de Uberlândia UFU, School of Dentistry, Department of Operative Dentistry and Dental Materials, Uberlandia, MG, Brazil.

Declaration of Interests: The authors certify that they have no commercial or associative interest that represents a conflict of interest in connection with the manuscript.

\section{Corresponding Author:}

Paulo Vinícius Soares

E-mail:paulovsoares@yahoo.com.br

hitps://doi.org/10.1590/1807-3107bor-2019.vol33.0115

Submitted: October 25, 2018

Accepted for publication: July 23, 2019

Last revision: November 5, 2019
Abstract: The aim of this study was to investigate how Brazilian dentists perceive and manage dentin hypersensitivity (DH) in their clinical routine. A 13-item questionnaire-based survey was developed and sent electronically to a convenience sample of dentists. The questionnaire assessed the personal and dental practice characteristics of the sample, the occurrence of DH in their daily clinical practice, and management strategies. The data were analyzed descriptively and together with the chi-square test $(\mathrm{a}=0.05)$. A total of 353 responses were obtained from September 2017 to March 2018. Of all the respondents, 62\% were females, $49.9 \%$ reported fewer than five years of dental practice, and $70.5 \%$ were self-identified as private practitioners. Most of the dentists reported an estimated frequency (30-60\%) of patients with DH in their practice. The most frequently cited $(91.79 \%)$ trigger of $\mathrm{DH}$ was air blast and/or scratching with a probe. The first-choice strategy to manage $\mathrm{DH}$ was a dentin desensitizer (48.16\%). The number of years in clinical practice did not influence DH relapse frequency $(p=0.76)$ significantly, or consider $\mathrm{DH}$ treatment as a problem $(\mathrm{p}=0.22)$. The present findings indicate that, regardless of clinical experience, dentists in Brazil still consider DH management a challenge in their daily dental practice. In addition, the results suggest that guidelines should be developed to disseminate the available knowledge regarding this condition in ways that may influence decision-making processes among practitioners.

Keywords: Dentin Sensitivity; Perception; Surveys and Questionnaires.

\section{Introduction}

The research carried out on dentin hypersensitivity (DH) has brought to light not only its widespread occurrence, but also its unclear nature. ${ }^{1,2} \mathrm{DH}$ prevalence rates range from $1.3 \%{ }^{3}$ to $84 \%,{ }^{4}$ with differences attributed to population settings and the diagnostic criteria used among studies. ${ }^{5,6,7}$ The pain associated with DH is characterized as short and sharp, arising when dentin is exposed to external (chemical, thermal, tactile, evaporative or osmotic) stimuli that cannot be attributed to any other dental defect or disease. ${ }^{8}$ According to the hydrodynamic theory, the stimulation of baroreceptors caused by fluid flow within dentin tubules leads to neural discharge, and is transmitted as a painful sensation. ${ }^{9} \mathrm{DH}$ tends to cause a negative impact in oral 
health-related routines, ${ }^{10}$ producing a significant impairment of patients' daily oral activities, like eating, drinking, toothbrushing and breathing. ${ }^{11}$ This undesirable influence ${ }^{12}$ is the main motivation that leads individuals to seek dental assistance to improve their quality of life. ${ }^{13}$

DH treatment is based on controlling or removing etiological factors, by way of occlusal adjustment, dietary advice, toothbrushing instruction and desensitizing agents. ${ }^{1,14} \mathrm{~A}$ large number of in-office DH treatment options have been reported to date, such as fluoride cavity varnishes, potassium-based agents, glutaraldehyde-based agents, oxalates, calcium phosphates, strontium or acetate chlorides, resinbased sealants and laser therapy. ${ }^{15}$ However, despite the wide-ranging agents available and approaches described in the literature, surveys worldwide $\mathrm{e}^{16,17,18,19,20,21}$ suggest knowledge gaps and failing confidence by dental professionals in managing $\mathrm{DH}$.

This situation turns decision-making into a challenge for dental practitioners, ${ }^{1,8,22}$ and raises the question of how to manage DH effectively in their daily practice. To the best of the authors' knowledge, there is no data in the current literature on Brazilian dentists' opinions regarding $\mathrm{DH}$. Therefore, the aim of this study was to investigate how Brazilian dentists perceive and manage $\mathrm{DH}$ in their clinical routine.

\section{Methodology}

\section{Questionnaire preparation}

This study was approved by the Institutional Research Ethics Committee (protocol 2.138.939). An electronic questionnaire was developed, based on previous studies conducting similar surveys $3,16,17,18,19,20,21,22$ that investigated dentists' perception and clinical routine regarding $\mathrm{DH}$. The first version of the questionnaire was piloted on a focus group comprising ten dentists to assess content validity. Feedback from the group included identifying ambiguous items and suggesting additional items. These aspects were not evaluated quantitatively; rather, items were edited to eliminate unclear questions and possible bias for production of the final version.

\section{Survey structure}

The final questionnaire consisted of 13 multiple choice questions organized in three sets, seeking information on a) dentists' personal (e.g. sex, level of education, and time of dental practice) and dental practice characteristics (public or private), b) $\mathrm{DH}$ in daily clinical practice (estimated frequency, predisposing factors and methods of assessment), and c) management strategies for $\mathrm{DH}$.

\section{Recruitment strategy}

The final questionnaire was sent electronically to a convenience sample of dental practitioners registered at a regional dental council in Brazil, using the Google Forms tool. The dentists were requested to click on the link to gain access to the survey. Informed consent was obtained from participants after including information concerning the purpose of the study, ensuring confidentiality, and relating its voluntary nature on the first page of the form. The dentists received no training to complete the questionnaire, with an estimated response time of 10 minutes. Data were collected electronically between September 2017 and March 2018.

\section{Data analysis}

The collected data were downloaded onto an Excel spreadsheet (Microsoft, Redmond, USA) to facilitate organization and analysis of the responses. A specially devised coding system was used to preserve confidentiality and keep questionnaire responses anonymous. The findings were calculated as frequencies of responses returned by dental practitioners. Statistical analyses were performed by using descriptive statistics and a chi-square test. A significance level of $5 \%$ was set, and all the analyses were performed using Sigma Plot, version 12.0.

\section{Results}

A total of 353 dentists correctly filled out the questionnaire; however, the response rate could not be established, because the exact number of dentists who received and opened their emails could not be determined. The findings of the study were divided according to the three sections of the form. 


\section{Personal and dental practice characteristics}

The details about absolute and relative frequencies for personal and dental practice characteristics are

Table 1. Personal and practice characteristics of Brazilian dentists participating in the study, by number and percentage of respondents replying to each item $(n=353)$.

\begin{tabular}{lcc}
\hline Characteristic & Number & Percentage \\
\hline Sex & & \\
Female & 219 & $62 \%$ \\
Male & 134 & $38 \%$ \\
Time of clinical practice (years) & & \\
Up to 5 & 176 & $49.9 \%$ \\
Between 6-10 & 45 & $12.7 \%$ \\
Between 11-20 & 80 & $22.7 \%$ \\
Between 21-30 & 37 & $10.5 \%$ \\
More than 30 & 15 & $4.2 \%$ \\
Highest level of education & & \\
Graduation & 87 & $24.7 \%$ \\
Specialization Course & 142 & $40.2 \%$ \\
MSc & 83 & $23.5 \%$ \\
PhD & 41 & $11.6 \%$ \\
Practice category & & \\
Private practice & 249 & $70.5 \%$ \\
Public practice & 104 & $29.5 \%$ \\
\hline
\end{tabular}

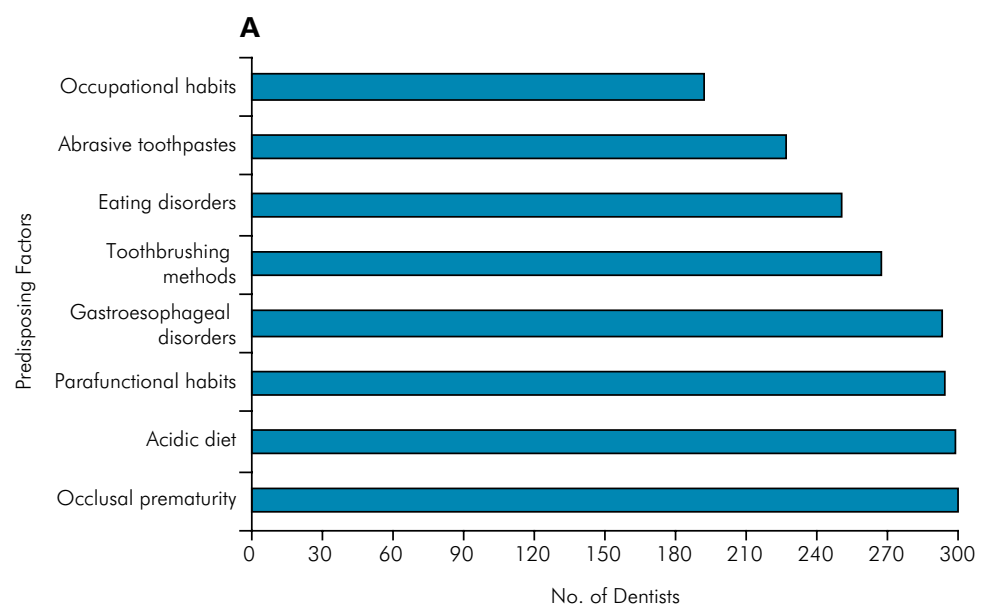

Note: Participants had the option to choose more than one answer. shown in Table 1 . The sample was mostly composed of females $(62 \%)$ who worked in dental practice fewer than five years (49.9\%), and who completed a specialization course $(40.2 \%)$ as their highest level of education. The majority of these dentists identified themselves as private practitioners (70.5\%).

\section{DH in daily clinical practice}

According to the questionnaire results, about $48 \%$ of the respondents reported that the estimated frequency of patients complaining about $\mathrm{DH}$ in their clinical practice ranged from 30 to $60 \%$. Interestingly, this percentage did not differ significantly across the practice category (chi-square test: $\mathrm{p}=0.61$ ).

The main predisposing DH-related factors expressed by practitioners is summarized in Figure 1A. Occlusal prematurity was the main factor selected, followed by acidic diet, parafunctional habits, and gastroesophageal disorders. Regarding the assessment methods, the responses indicate that air blast and/or scratching of the tooth with a dental probe were the most frequently cited triggers $(91.79 \%)$ of clinical DH. The least common assessment method was vertical and horizontal percussion (0.85\%) (Figure 1B).

\section{DH management strategies}

Regarding the strategies used to manage $\mathrm{DH}$, most dentists (48.16\%) reported dentin desensitizers

Figure 1. A. Most frequent $\mathrm{DH}$ predisposing factors, according to respondents. B. Assessment methods used to diagnose $\mathrm{DH}$, as indicated by the practitioners. 
as their first choice, followed by the association of dentin desensitizers to laser therapy $(26.63 \%)$, and desensitizing toothpaste used alone (14.73\%). Interestingly, 32 dentists (almost 10\%) reported that they did not administer DH treatment in their clinical practice (Figure 2A). In addition, the majority $(45 \%)$ of the respondents stated that they recommended the use of desensitizing toothpaste during and after completing treatment (Figure 2B). When asked about the action mechanisms of dentin desensitizers, respondents cited neural and tubule-blocking agents (39.86\%) as the most widely known. However, and surprisingly, $29 \%$ of the dentists reported that they did not know different classifications of dentin desensitizers, and 3.4\% did not know any type of desensitizing agents (Figure
2C). When questioned about what kind of advice or recommendations they offered to their patients, the most commonly chosen answers were toothbrushing education, parafunctional habit control and acidic diet changes (Figure 2D).

Finally, the number of years of clinical practice was not found to bear significant influence on $\mathrm{DH}$ relapse frequency after treatment was completed (chi-square test: $p=0.76$ ) (Table 2). In addition, the dentists researched still considered DH management a challenge in their clinical practice, regardless of their time of professional experience (chi-square test: $p=0.22$ ). The main reason reported for their discomfort in having to manage this challenge was that pain is subjective, and there is no consolidated protocol for DH treatment (Figure 3).
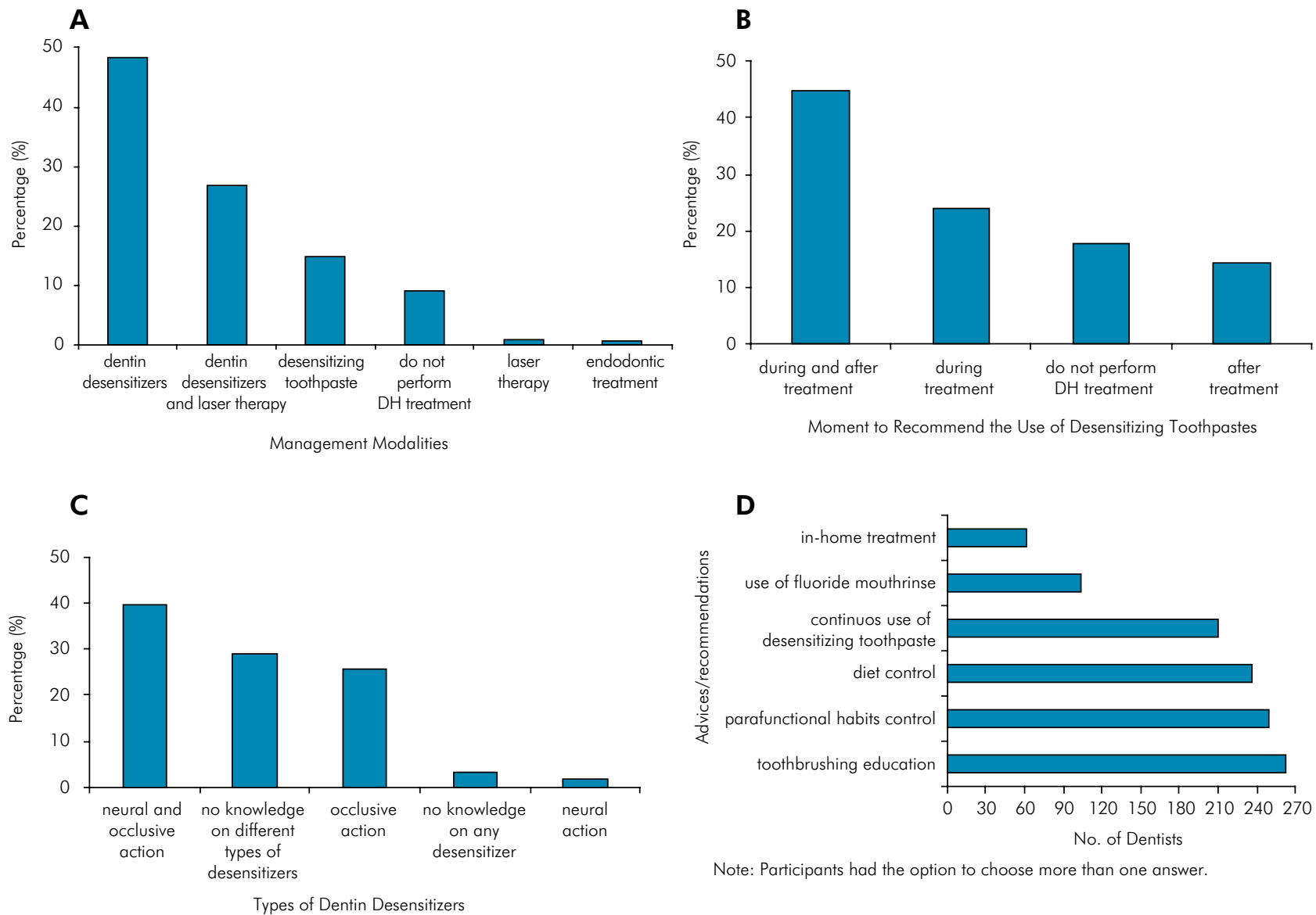

Figure 2. A. Management modalities used routinely when treating $\mathrm{DH}$. B. When to recommend desensitizing toothpastes. $\mathrm{C}$. Types of dentin desensitizers known by the respondents. D. Advice/recommendations offered to patients during $\mathrm{DH}$ management, according to dentists surveyed. 


\section{Discussion}

There is growing awareness that $\mathrm{DH}$ is an increasingly important issue, affecting the quality of life ${ }^{13}$ of many individuals worldwide. It must be addressed from both a diagnostic and management perspective. ${ }^{23}$ Previous studies developed in different regions of Brazil showed $\mathrm{DH}$ prevalence rates ranging from $17 \%$ to $89.1 \% .{ }^{24,25,26,27,28}$ This report was the first to investigate the current practice of Brazilian dental practitioners regarding DH management. Such knowledge can serve as a valuable basis for developing

Table 2. Analysis between years of clinical practice and frequency of dentin hypersensitivity relapse after conclusion of treatment $(\mathrm{n}=353)$.

\begin{tabular}{lcccc}
\hline \multirow{2}{*}{ Variable } & \multicolumn{3}{c}{ DH frequency of relapse } & p-value \\
\cline { 2 - 4 } & $<30 \%$ & $30-50 \%$ & $>50 \%$ & \\
\cline { 1 - 3 } Years of dental practice & & & & \\
Up to 5 & 82 & 78 & 16 & \\
$6-10$ & 22 & 20 & 3 & \\
$11-20$ & 41 & 36 & 3 & 0.76 \\
$21-30$ & 22 & 13 & 2 & \\
$>30$ & 7 & 6 & 2 & \\
Total & 174 & 153 & 26 & \\
& $(49.2 \%)$ & $(43.3 \%)$ & $(7.3 \%)$ & \\
\hline
\end{tabular}

ongoing professional educational strategies to help clinicians in the decision-making process, and to guide researchers in designing future epidemiological, clinical study and prevention strategies. ${ }^{29,30}$

The findings of this study showed that, regardless of the practice category (public or private), $48 \%$ of the respondents considered $\mathrm{DH}$ a common condition (an overall estimated prevalence range of $30-60 \%$ ) in their clinical practice. These findings are of significant concern, and are in agreement with the rates found in previous epidemiological studies..$^{24,25,26,27,28}$ In addition, most Brazilian dentists were aware of the importance of predisposing factors, such as stress, corrosion and friction, ${ }^{31}$ in the etiology of $\mathrm{DH}$, and believe that they must be taken into account in devising management strategies. ${ }^{1,8}$ Accurate DH diagnosis requires dental professionals to exclude any confounding factors from other orofacial pain conditions, such as dental caries, pulpitis, fractured restorations, postoperative sensitivity, marginal leakage and gingival inflammation, to ensure better diagnosis. ${ }^{8}$ In this study, almost $92 \%$ of the dentists cited air blast and/ or scratching the tooth with a dental probe as triggers of clinical DH, as corroborated by the literature. ${ }^{1,8}$

Regarding possible management strategies, despite the large number of agents and materials available on the market, the issues associated with $\mathrm{DH}$ in

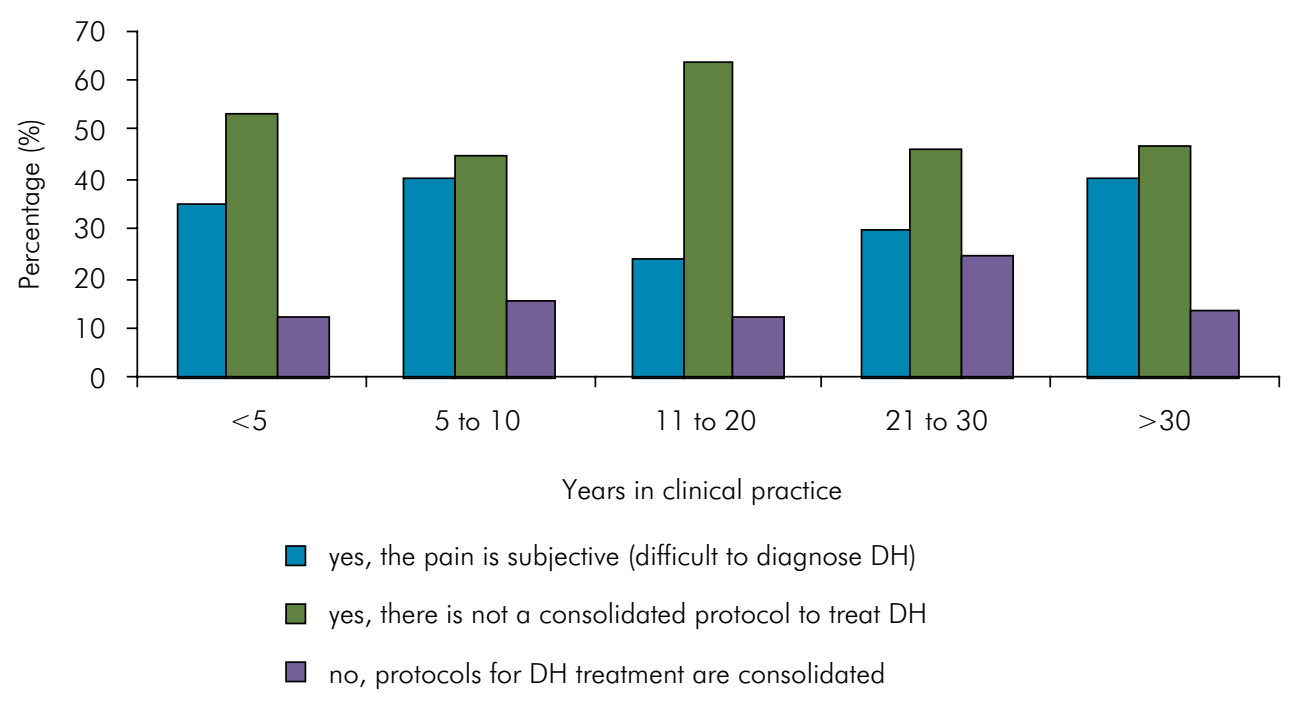

Figure 3. Dental practitioners' responses to the question: "Do you consider the management of dentin hypersensitivity a challenge in your daily clinical practice?" presented according to their years of dental practice. 
general dental practice can be very challenging. ${ }^{30}$ Different action mechanisms of desensitizers have been identified; their overall aim is to reduce the fluid flow within dentinal tubules by obliterating them or blocking the neural responses triggering the pain response. ${ }^{15}$ However, there is no desensitizing agent or management strategy that can be currently deemed as ideal for all patients in reducing or eliminating $\mathrm{DH}$, and used as the gold standard treatment. ${ }^{32}$ This being the case, clinicians are still uncertain as to what products can offer their patients clinical benefits.

In this survey, respondents were asked about the action mechanisms of dentin desensitizers, and cited neural and tubule-blocking agents $(39.86 \%)$ as the most widely known. On the other hand, $29 \%$ of the dentists reported not recognizing the different classifications of desensitizers, and 3.4\% did not know any type of desensitizing agent - a finding of significant concern. Correct management of a condition requires the clinician to be aware of and understand the several different approaches and agents available on the market. Only in this way can they be confident in their ability to treat the problem, and to apply the best strategy to each clinical situation. An important consideration is that the information about $\mathrm{DH}$ products is usually provided by the manufacturing companies, ${ }^{1}$ and the basing of decisions to change clinical practice strategies on scientific evidence poses a challenge to some dentists, ${ }^{33}$ who still make decisions based on their previous experiences or opinions from colleagues. ${ }^{34}$ Furthermore, clinicians tend to simply recommend a treatment (such as the application of desensitizing agents) without first modifying or eliminating the etiological and predisposing factors involved in the process. In this phase, the joint working relationship between the professional and the patient is essential, since behavioral changes in diet and dental hygiene (e.g. use of specific toothpaste), and control of parafunctional habits may be needed. ${ }^{35,36}$

In addition, regardless of the years of dental practice, more than $80 \%$ of the dentists included in this study seemed to have concerns about DH-related issues, and consider its management as a challenge in their daily dental practice. This situation serves as an alert to the ineffective transfer of knowledge from research to clinical dental practice. ${ }^{37}$ It is a call to the awareness that scientific evidence must be communicated to dentists or well disseminated, to enable them to provide their patients with the best possible treatment. ${ }^{38,39}$ For this reason, continuing training education programs should be encouraged to keep dental clinicians abreast of the latest developments, and to prepare future professionals to seek out the best available scientific evidence on issues and challenges associated with $\mathrm{DH}$. In addition, the authors recommend that efforts should be made to develop practical and simple guidelines ${ }^{8,29}$ in Portuguese, to help clinicians manage DH successfully in their daily clinical practice, so that they can ensure their patients a better quality of life. ${ }^{8,40}$

Although this survey was carried out using a convenience sample of dentists, it included professionals from both private and public practice, and with different clinical experience. The findings presented here may not be generalized enough to apply to all dentists, but they represent an initial attempt to investigate Brazilian dentists' perception of and management strategies for DH. Further investigations involving larger sample sizes should be conducted to support these findings, and to broaden our knowledge of this issue in Brazil.

\section{Conclusion}

Within the limitations of this study, the present findings indicate that, regardless of their clinical experience, dentists in Brazil still consider the management of $\mathrm{DH}$ a challenge in their daily dental practice. The results also suggest that guidelines should be developed to disseminate the current knowledge about DH in ways that may influence the decision-making process among practitioners. Given the increasing prevalence of $\mathrm{DH}$ in clinical practice, efforts should be made to educate undergraduate students, and to keep dental professionals abreast of the latest management approaches to this condition.

\section{Acknowledgments}

This study was financed in part by the Coordenação de Aperfeiçoamento de Pessoal de Nível Superior Brasil (CAPES) - Financial Code 001. The authors would like to thank the participating dentists for taking the time to respond to the survey. 


\section{References}

1. Gillam DG. A new perspective on dentine hypersensitivity: guidelines for general dental practice. Dent Update 2017 Jan; 44(1):33-6, 9-42. https://doi.org/10.12968/denu.2017.44.1.33

2. West NX. Dentine hypersensitivity: preventive and therapeutic approaches to treatment. Periodontol 2000. 2008;48(1):31-41. https://doi.org/10.1111/j.1600-0757.2008.00262.x

3. Bamise CT, Olusile AO, Oginni AO, Dosumu OO. The prevalence of dentine hypersensitivity among adult patients attending a Nigerian teaching hospital. Oral Health Prev Dent. 2007;5(1):49-53.

4. Chabanski MB, Gillam DG, Bulman JS, Newman HN. Prevalence of cervical dentine sensitivity in a population of patients referred to a specialist Periodontology Department. J Clin Periodontol. 1996 Nov;23(11):989-92. https://doi.org/10.1111/j.1600-051X.1996.tb00525.x

5. Rees JS, Addy M. A cross-sectional study of buccal cervical sensitivity in UK general dental practice and a summary review of prevalence studies. Int J Dent Hyg. 2004 May;2(2):64-9. https://doi.org/10.1111/j.1601-5029.2004.00068.x

6. Splieth $\mathrm{CH}$, Tachou A. Epidemiology of dentin hypersensitivity. Clin Oral Investig. 2013 Mar;17(S1 Suppl 1):S3-8. https://doi.org/10.1007/s00784-012-0889-8

7. West NX, Sanz M, Lussi A, Bartlett D, Bouchard P, Bourgeois D. Prevalence of dentine hypersensitivity and study of associated factors: a European population-based cross-sectional study. J Dent. 2013 Oct;41(10):841-51. https://doi.org/10.1016/i.jdent.2013.07.017

8. Canadian Advisory Board on Dentin Hypersensitivity. Consensus-based recommendations for the diagnosis and management of dentin hypersensitivity. J Can Dent Assoc. 2003 Apr;69(4):221-6.

9. Brännström M, Lindén LA, Aström A. The hydrodynamics of the dental tubule and of pulp fluid. A discussion of its significance in relation to dentinal sensitivity. Caries Res. 1967;1(4):310-7. https://doi.org/10.1159/000259530

10. Bekes K, John MT, Schaller HG, Hirsch C. Oral health-related quality of life in patients seeking care for dentin hypersensitivity. J Oral Rehabil. 2009 Jan;36(1):45-51. https://doi.org/10.1111/j.1365-2842.2008.01901.x

11. Boiko OV, Baker SR, Gibson BJ, Locker D, Sufi F, Barlow AP, et al. Construction and validation of the quality of life measure for dentine hypersensitivity (DHEQ). J Clin Periodontol. 2010 Nov;37(11):973-80. https://doi.org/10.1111/i.1600-051X.2010.01618.x

12. Bekes K, Hirsch C. What is known about the influence of dentine hypersensitivity on oral health-related quality of life? Clin Oral Investig. 2013 Mar;17(S1 Suppl 1):S45-51. https://doi.org/10.1007/s00784-012-0888-9

13. Douglas-de-Oliveira DW, Vitor GP, Silveira JO, Martins CC, Costa FO, Cota LO. Effect of dentin hypersensitivity treatment on oral health related quality of life - A systematic review and meta-analysis. J Dent. 2018 Apr;71:1-8. https://doi.org/10.1016/i.jdent.2017.12.007

14. Shiau HJ. Dentin hypersensitivity. J Evid Based Dent Pract. 2012 Sep;12(3 Suppl):220-8. https://doi.org/10.1016/S1532-3382(12)70043-X

15. Moraschini V, Costa LS, Santos GO. Effectiveness for dentin hypersensitivity treatment of non-carious cervical lesions: a meta-analysis. Clin Oral Investig. 2018 Mar;22(2):617-31. https://doi.org/10.1007/s00784-017-2330-9

16. Gillam DG, Seo HS, Bulman JS, Newman HN. Perceptions of dentine hypersensitivity in a general practice population. J Oral Rehabil. 1999 Sep;26(9):710-4. https://doi.org/10.1046/i.1365-2842.1999.00436.x

17. Amarasena N, Spencer J, Ou Y, Brennan D. Dentine hypersensitivity - Australian dentists' perspective. Aust Dent J. 2010 Jun;55(2):181-7. https://doi.org/10.1111/j.1834-7819.2010.01223.x

18. Schuurs AH, Wesselink PR, Eijkman MA, Duivenvoorden HJ. Dentists' views on cervical hypersensitivity and their knowledge of its treatment. Endod Dent Traumatol. 1995 Oct;11(5):240-4. https://doi.org/10.1111/j.1600-9657.1995.tb00496.x

19. Gillam DG, Bulman JS, Eijkman MA, Newman HN. Dentists' perceptions of dentine hypersensitivity and knowledge of its treatment. J Oral Rehabil. 2002 Mar;29(3):219-25. https://doi.org/10.1046/i.1365-2842.2002.00812.x

20. Kopycka-Kedzierawski DT, Meyerowitz C, Litaker MS, Chonowski S, Heft MW, Gordan VV, et al. Management of dentin hypersensitivity by National Dental Practice-Based Research Network practitioners: results from a questionnaire administered prior to initiation of a clinical study on this topic. BMC Oral Health. 2017 Jan;17(1):41. https://doi.org/10.1186/s12903-017-0334-0

21. Benoist FL, Ndiaye FG, Faye B, Bane K, Ngom Pl, Ndong PM. Knowledge of and management attitude regarding dentin hypersensitivity among dentists from a West African country. J Contemp Dent Pract. 2014 Jan;15(1):86-91. https://doi.org/10.5005/ip-journals-10024-1493

22. Cunha-Cruz J, Wataha JC, Zhou L, Manning W, Trantow M, Bettendorf MM, et al. Treating dentin hypersensitivity: therapeutic choices made by dentists of the northwest PRECEDENT network. J Am Dent Assoc. 2010 Sep;141(9):1097-105. https://doi.org/10.14219/jada.archive.2010.0340

23. Cummins D. Dentin hypersensitivity: from diagnosis to a breakthrough therapy for everyday sensitivity relief. J Clin Dent. 2009;20(1):1-9. PMID:19489186 
24. Costa RS, Rios FS, Moura MS, Jardim JJ, Maltz M, Haas AN. Prevalence and risk indicators of dentin hypersensitivity in adult and elderly populations from Porto Alegre, Brazil. J Periodontol. 2014 Sep;85(9):1247-58. https://doi.org/10.1902/jop.2014.130728

25. Fischer C, Fischer RG, Wennberg A. Prevalence and distribution of cervical dentine hypersensitivity in a population in Rio de Janeiro, Brazil. J Dent. 1992 Oct;20(5):272-6. https://doi.org/10.1016/0300-5712(92)90043-C

26. Scaramucci T, Anfe TEA, Ferreira SS, Frias AC, Sobral MA. Investigation of the prevalence, clinical features, and risk factors of dentin hypersensitivity in a selected Brazilian population. Clin Oral Investig. 2014;18(2):651-7. https://doi.org/10.1007/s00784-013-1008-1

27. Teixeira DN, Zeola LF, Machado AC, Gomes RR, Souza PG, Mendes DC, et al. Relationship between noncarious cervical lesions, cervical dentin hypersensitivity, gingival recession, and associated risk factors: A cross-sectional study. J Dent. 2018 Sep;76:93-7. https://doi.org/10.1016/i.jdent.2018.06.017

28. Yoshizaki KT, Francisconi-Dos-Rios LF, Sobral MA, Aranha AC, Mendes FM, Scaramucci T. Clinical features and factors associated with non-carious cervical lesions and dentin hypersensitivity. J Oral Rehabil. 2017 Feb;44(2):112-8. https://doi.org/10.1111/joor.12469

29. Gillam D, Chesters R, Attrill D, Brunton P, Slater M, Strand P et al. Dentine hypersensitivity--guidelines for the management of a common oral health problem. Dent Update 2013 Sep;40(7):514-6, 8-20, 23-4.

30. Orchardson R, Gillam DG. Managing dentin hypersensitivity. J Am Dent Assoc. 2006 Jul;137(7):990-8. https://doi.org/10.14219/jada.archive.2006.0321

31. Grippo JO, Simring M, Coleman TA. Abfraction, abrasion, biocorrosion, and the enigma of noncarious cervical lesions: a 20-year perspective. J Esthet Restor Dent. 2012 Feb;24(1):10-23. https://doi.org/10.1111/i.1708-8240.2011.00487.x

32. West NX, Seong J, Davies M. Management of dentine hypersensitivity: efficacy of professionally and self-administered agents. J Clin Periodontol. 2015 Apr;42 Suppl 16:S256-302. https://doi.org/10.1111/icpe.12336

33. Gonçalves AP, Correa MB, Nahsan FP, Soares CJ, Moraes RR. Use of scientific evidence by dentists in Brazil: room for improving the evidence-based practice. PLoS One. 2018 Sep;13(9):e0203284. https://doi.org/10.1371/journal.pone.0203284

34. Kao RT. The challenges of transferring evidence-based dentistry into practice. J Evid Based Dent Pract. 2006 Mar;6(1):125-8. https://doi.org/10.1016/j.jebdp.2005.12.011

35. Sharif MO, Iram S, Brunton PA. Effectiveness of arginine-containing toothpastes in treating dentine hypersensitivity: a systematic review. J Dent. 2013 Jun;41(6):483-92. https://doi.org/10.1016/i.jdent.2013.01.009

36. Beddis H, Soneji P, Welford S, Ashley M. Making sense of sensitivity. Dent Update 2013 Jun;40(5):403-4, 6-8, 11. https://doi.org/10.12968/denu.2013.40.5.403

37. Straub-Morarend CL, Wankiiri-Hale CR, Blanchette DR, Lanning SK, Bekhuis T, Smith BM, et al. Evidence-Based Practice Knowledge, Perceptions, and Behavior: A Multi-Institutional, Cross-Sectional Study of a Population of U.S. Dental Students. J Dent Educ. 2016 Apr;80(4):430-8.

38. Emrick JJ, Gullard A. Integrating research into dental student training: a global necessity. J Dent Res. 2013 Dec;92(12):1053-5. https://doi.org/10.1177/0022034513508557

39. lacopino AM. The influence of "new science" on dental education: current concepts, trends, and models for the future. J Dent Educ. 2007 Apr;71(4):450-62.

40. Davari A, Ataei E, Assarzadeh H. Dentin hypersensitivity: etiology, diagnosis and treatment; a literature review. J Dent (Shiraz). 2013 Sep;14(3):136-45. 